\title{
The Impact Performance of Bamboo Oriented Strand Board and Computed Tomography Technique for Detecting Internal Damage
}

\author{
Yuhui Sun,* Zehui Jiang,* Xiubiao Zhang, Zhengjun Sun, Xiaomeng Yang, and \\ Huanrong Liu*
}

\begin{abstract}
The objective of this study was to investigate the impact performance of bamboo oriented strand board under different impact energy. Bamboo oriented strand board with two types of strand orientation distribution, both with mainly parallel aligned strand orientation (LVSL) and three-layer assembly with orthogonally oriented strands (BOSB), were prepared. The impact properties of the boards, both untreated and treated with submersion, were investigated at seven energy levels. Additionally, the damage morphology was characterized using an X-ray computed tomography (CT) scanner. The results indicated that BOSB provided a larger maximum load carrying capacity, and represented superior impact properties compared to LVSL. The shapes of force/energy-time history of BOSB and LVSL were different from projectile energy levels, and they were related to the specimen destruction forms via CT scanning. Moreover, CT scanning revealed that LVSL and BOSB exhibited similar damage behaviors, which mainly included delamination and fibers breakage. The dent depth of BOSB on the impact site was less than LVSL's for touch types, and there was more internal fracture inside the layers of LVSL at relatively higher energy levels of $300 \mathrm{~J}$ and $450 \mathrm{~J}$. Furthermore, BOSB still exhibited better impact performance than LVSL under the condition of submersion.
\end{abstract}

Keywords: Bamboo oriented strand board; Strand orientation distribution; impact property; Submersion; CT scanning

Contact information: International Centre for Bamboo and Rattan, Beijing, China, 100102;

*Corresponding authors: 4651309797@qq.com; jiangzehui@icbr.ac.cn; liuhuanrong@icbr.ac.cn. Equal contribution to this study: Zehui Jiang and Huanrong Liu.

\section{INTRODUCTION}

Bamboo is abundantly available in many countries, and it is a very promising substitution material for wood due to its rapid growth rate, short rotation age, high tensile strength, and traditional usage as a building material (Dixon et al. 2017). Bamboo oriented strand board is one of the most effective and efficient approaches, and it can be exploited as an industrial material as a substitute for traditional wood structural board (Du and Xie 2010; Chaowana 2013). It has the advantages of high strength, good dimensional stability, and uniformity. Typical wood structural components are known to be susceptible to various loading types during their service life. Among them, the most serious and complex is the impact loading. Examples include primary structures exposed to hail impacts and cargo floors exposed to luggage impact. The application of multiple impacts on a single location may exaggerate the loading problem, as invisible damage of various kinds occurs easily in the composites, reducing the structural stiffness and strength (Avila et al. 2007; González 
et al. 2011). In other situations, strandboards may be in direct contact with weather and moisture exposure that may occur during construction as well as the natural humidity fluctuations that occur in floors, roofs, and walls. Especially, strandboards may be left outdoors during construction in the rainy seasons for a certain period, and this may be followed by opportunities for the wood fiber to dry to moisture content levels below 20 percent. The wet-dry cycle may affect the long-term performance of strandboards, possibly causing severe reduction of impact property. Therefore, the impact property of strandboards after the environment changes should be specified.

Currently, much of the bamboo oriented strand board (bamboo OSB) research presented in literature describes the basic static physical and mechanical properties of OSB, but it rarely encompasses its impact resistance (Stürzenbecher et al. 2010; Alldritt et al. 2013; Ihak et al. 2015; Semple et al. 2015; Chen and He 2017). However, the impact properties, failure mode, and damage mechanisms of bamboo-based composites, such as bamboo-wood composite materials, bamboo scrimber, and bamboo fibre-reinforced plastic composite, have been preliminarily studied both in China and abroad. The impact resistance of composites can be improved when bamboo serves as the enhancement material (Zhu et al. 2005). Diverse technological parameters, such as board structure and density, have been shown to produce an effect on the impact properties and failure mode of bamboo-based composites (Yu et al. 2012). Principle types of damage in composite materials are generally characterized by matrix cracking, fiber-matrix interface debonding, delamination, and fiber breakage (Jain et al. 1992; Liu et al. 2016). In other applications, structural insulated panel with OSB skins have been the subject of research about its capacity to resist windborne debris impact. The test results indicated two types of failure modes, i.e. punching shear failure and flexural failure of the back OSB skin (Terentiuk and Memari 2012; Meng et al. 2016).

Particularly, low-velocity impact can leave minimal visible marks on the impacted surface, but it can easily produce delaminations and matrix cracks that may be invisible on the internal structure (Maio et al. 2013). For multilayer structural board, the internal impact damage is mostly confined to a relatively small area surrounding the location of impact, and the damage size is always smaller than the size of the visible plastically deformed indent exposed at the outer layers (Tooski et al. 2013). Together these failures can have a deleterious effect on the mechanical and physical properties of the composites. To better characterize the extent of the damage, X-ray computed tomography (CT), a non-destructive testing method, is used to detect damage in bamboo OSB specimens after the impact loading (Mei et al. 2015). The CT scanning uses ultrasonic propagation characteristics to reveal the internal defects or damage of materials. Some of the key uses for CT scanning have been flaw detection, failure analysis, metrology, assembly analysis, image-based finite element methods, and reverse engineering applications (Evans et al. 2015; Skog 2016). Computed tomography accurately detects tiny density differences between various organizations in a cross-sectional anatomical plane of bamboo OSB. The density of the bamboo strand, adhesive, and gap are not identical. Among them, the gap density is equal to air. However, studies observing the fracture behavior of the impact test specimens using CT technology are not clear-cut or available. Making sufficient use of CT technology can achieve relatively high detection precision in the internal structure of specimens.

The main goal of this work is to present and discuss some experimental results obtained during a low-velocity impact testing campaign conducted on boards with two kinds of structures. Drop dart tests were conducted by selecting different levels for the dart kinetic energy at impact by modifying the drop height. Then, CT technology was applied 
to observe the impact fracture behavior. In addition, the impact property of both boards treated with submersion was investigated. Although rare, when boards are directly immersed in practical use, the impact performance ability to respond to changes in ambient humidity could be roughly judged through measurement of the impact performance of panels treated with submersion. Data support was provided for boards used in a high moisture environment. Hence, a comprehensive understanding of the impact behavior is essential to the design and manufacturing of novel bamboo OSB.

\section{EXPERIMENTAL}

\section{Materials}

The samples comprised of 2- to 7-year-old bamboo (Dendrocalamus giganteus Munro) that were collected from Mangshi, Yunnan, China. The strands were produced using a wood planer. The strand length, width, and thickness were prepared at $140 \mathrm{~mm}$ to $145 \mathrm{~mm}, 5 \mathrm{~mm}$ to $60 \mathrm{~mm}$, and $0.4 \mathrm{~mm}$ to $0.8 \mathrm{~mm}$, respectively. The strands were air-dried, and the strand moisture content was $5 \%$. Emulsion polymer isocyanate adhesive (Taier Corporation, Beijing, China) was used with a mass fraction of $6 \%$ based on the oven-dry strand mass.

\section{Production of strandboards}

The strandboards were produced at beltline scale with a hydraulic hot press (Lutong Machinery Corporation, Wuxi, China). The strandboards were produced with the dimensions of $2400 \mathrm{~mm} \times 1200 \mathrm{~mm} \times 12 \mathrm{~mm}$ and the target density of $0.9 \mathrm{~g} \cdot \mathrm{cm}^{-3}$

The produced boards differed in strand orientation distribution. Two distinctive orientation types were considered, namely parallel aligned strand orientation (LVSL) and a typical three-layer assembly with aligned strands in the face layers and orthogonally oriented strands in the core layer, including the weight ratio of face-to-core-to-back layers set at 1:2:1 (BOSB). Diagrams of the two types are shown in Fig.1.

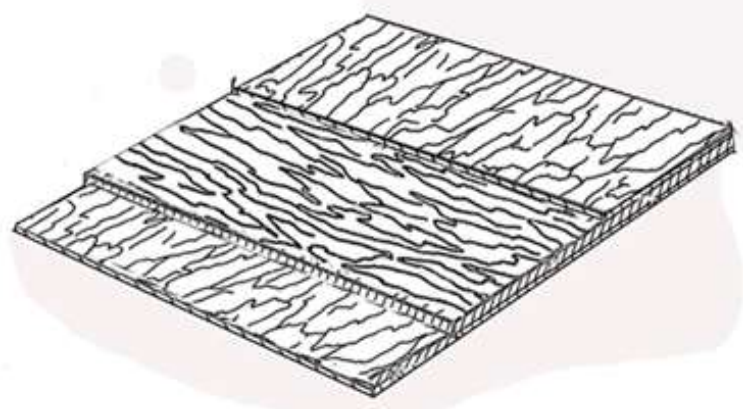

a. BOSB

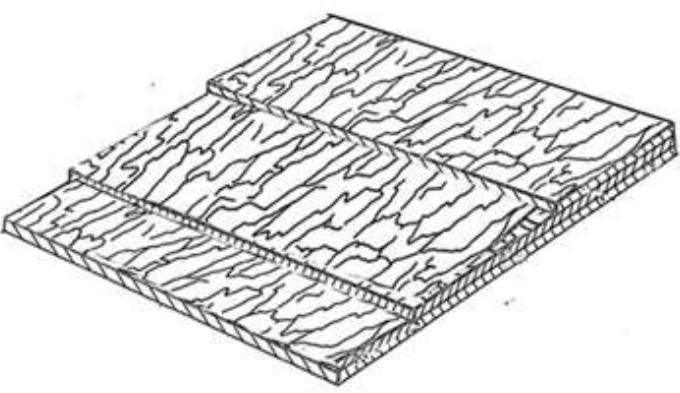

b. LVSL

Fig. 1. Strand alignment pattern

The board was hot pressed at $140{ }^{\circ} \mathrm{C}$ to $145^{\circ} \mathrm{C}$ and $3 \mathrm{MPa}$ to $4 \mathrm{MPa}$ pressure for 6 min. The pressing process was controlled by platen distance, and cooling the strandboards under moderate pressure prevented the occurrence of damp blisters. Afterwards, the board was conditioned for 10 days in a room adjusted to $25{ }^{\circ} \mathrm{C}$ to $30{ }^{\circ} \mathrm{C}$ and $60 \%$ to $65 \%$ relative humidity $(\mathrm{RH})$ to reach moisture content of about $12 \%$. 


\section{Methods}

Low-velocity impact tests

The low-speed impact experiment was conducted in accordance with ASTM D7136 (2015) and ASTM D3763 (2015). The impact tests were performed using a drop weight impact test machine (Dynatup 9250HV; Instron, Boston, MA, USA). The low-velocity impact is an impact event that is long enough for the whole structure to respond to the impactor by elastically absorbing energy. A conical-shaped steel dart with $3.54 \mathrm{~kg}$ weight and a hemispherical nose with a $12.7-\mathrm{mm}$ radius were used in the tests. An accelerometer was embedded inside the hammer just above the impactor tip to determine the velocity and displacement history. The projectiles were directed normal to the specimens' plane at seven energy levels, namely $50 \mathrm{~J}, 100 \mathrm{~J}, 150 \mathrm{~J}, 200 \mathrm{~J}, 250 \mathrm{~J}, 300 \mathrm{~J}$, and up to $450 \mathrm{~J}$. The dimensions of specimens for impact test were $100 \mathrm{~mm} \times 100 \mathrm{~mm} \times 28 \mathrm{~mm}$.

The test of wet-dry cycle was as follows, specimens were immersed in cold water $\left(25^{\circ} \mathrm{C}\right.$ ) for approximately $24 \mathrm{~h}$, and dried by letting the panels air dry for three months. The treated panels were conditioned as above to reach moisture content of about $12 \%$. A total of 6 replicates were used for untreated and treated strandboards.

The device monitored contact force, generated curve of energy absorbed by the specimen versus time, the absorbed energy $E(t)$ at time $t$ was determined by Eq. 1,

$$
E(t)=\frac{1}{2} \times m \times\left(v_{0}^{2}-v_{\mathrm{t}}^{2}\right)
$$

where $E(t)$ is the absorbed energy $(\mathrm{J}), m$ is the mass of the impactor $(\mathrm{kg}), v_{0}$ is its initial velocity at the contact time $(\mathrm{m} / \mathrm{s})$, and $v_{\mathrm{t}}$ is the impactor velocity at time $t(\mathrm{~m} / \mathrm{s})$.

\section{$X$-ray CT scanner testing}

The X-ray CT scanner was manufactured by American General Electric Company (Boston, USA), and the model was as follows: Bright Speed Excel 4 spiral CT, $120 \mathrm{kV}$ voltage, $160 \mathrm{~mA}$ current, layer thickness $2.5 \mathrm{~mm}$, window width $2000 \mathrm{HU}$ and window level $30 \mathrm{HU}$, reconstruction algorithm Bone. The experimental cross-sectional damage morphology of bamboo OSB after the impact was analyzed using a high precision test analysis of CT scanner.

\section{RESULTS AND DISCUSSION}

\section{Impact Performance of Untreated Bamboo OSB}

As shown in Table 1, while increasing the actual incipient impact energy from 50 $\mathrm{J}$ to $450 \mathrm{~J}$, the total energy, energy at fracture, and total time of BOSB and LVSL gradually increased. Due to the brittle nature of the material, large amounts of energy were absorbed in plastic deformation and through damage mechanisms. The impact energy of $50 \mathrm{~J}$ fell short of the required peak load and the energy at peak load for the BOSB and LVSL samples. Nevertheless, the peak load for BOSB was noticeably greater than that of LVSL. When the impact energy was $100 \mathrm{~J}$ to $450 \mathrm{~J}$, the average peak load BOSB (19809.12 N) was greater than LVSL $(18752.00 \mathrm{~N})$, as the BOSB's crisscrossed structure form provided a larger maximum load carrying capacity.

The impact energy ( $450 \mathrm{~J}$ ) achieved the required fracture energy, and the specimens were completely destroyed. The total absorbing energy and energy at fracture for BOSB 
were 1.22 times and 1.34 times that of LVSL, respectively, as the crisscrossed structure of BOSB increased its anti-fracture performance. These results indicated that the impact properties of BOSB were superior to those of LVSL. Similar results appeared in bamboo bundle laminated veneer lumber and wood veneer/polyester composites (Chen et al. 2014; APA Haghdan et al. 2015). When the stress wave acted on the plate's thickness direction, the meridional stresses of each position in the cross-laminated structure were not identical, leading to in-plane discontinuous stiffness and often producing transverse shear stress. Finally, the delamination damage burst, which resulted in continuous energy accumulation. Simultaneously, the cross-laminated structure effectively dispersed stress, which inhibited the development of micro-cracks in the interfacial and pavement layers, increased the resistance to transversal expansion of the crack, and incorporated more energy.

Table 1. Impact Data of BOSB and LVSL

\begin{tabular}{|c|c|c|c|c|c|c|}
\hline \multirow{3}{*}{ Specimens } & $\begin{array}{c}\text { Nominal } \\
\text { Impact } \\
\text { Energy(J) }\end{array}$ & Total Energy $(\mathrm{J})$ & $\begin{array}{c}\text { Energy at } \\
\text { Fracture }(\mathrm{J})\end{array}$ & $\begin{array}{c}\text { Energy at Peak } \\
\text { Load }(\mathrm{J})\end{array}$ & Peak Load (N) & $\begin{array}{c}\text { Total Time } \\
\text { (ms) }\end{array}$ \\
\hline \multirow{5}{*}{ BOSB } & 50.00 & $45.65(0.98)$ & $46.45(0.89)$ & $47.5(0.68)$ & $15741.22(2129.03)$ & $8.01(1.23)$ \\
\cline { 2 - 7 } & 100.00 & $95.17(1.12)$ & $96.21(1.04)$ & $85.34(0.62)$ & $18509.42(498.51)$ & $8.54(0.08)$ \\
\cline { 2 - 7 } & 150.00 & $145.03(0.83)$ & $146.44(0.64)$ & $86.74(11.01)$ & $21352.01(929.85)$ & $9.39(0.19)$ \\
\cline { 2 - 7 } & 200.00 & $197.98(2.01)$ & $198.9(1.77)$ & $109.00(0.29)$ & $19334.01(1885.57)$ & $9.61(0.67)$ \\
\cline { 2 - 7 } & 250.00 & $257.36(0.22)$ & $257.76(0.14)$ & $89.13(14.98)$ & $17221.00(1272.09)$ & $13.38(0.92)$ \\
\cline { 2 - 7 } & 300.00 & $307.92(2.77)$ & $308.59(1.72)$ & $83.05(10.01)$ & $19840.91(2964.33)$ & $10.78(5.72)$ \\
\cline { 2 - 7 } & 450.00 & $468.26(12.24)$ & $437.10(10.08)$ & $70.16(20.26)$ & $22597.40(2244.06)$ & $19.22(0.83)$ \\
\hline \multirow{5}{*}{ LVSL } & 50.00 & $48.05(0.57)$ & $48.57(0.54)$ & $47.54(0.74)$ & $11261.91(1743.58)$ & $10.45(1.08)$ \\
\cline { 2 - 7 } & 100.00 & $96.79(1.85)$ & $97.57(1.76)$ & $92.25(2.3)$ & $17945.21(69.44)$ & $8.47(0.04)$ \\
\cline { 2 - 7 } & 150.00 & $147.17(1.34)$ & $148.19(1.35)$ & $108.98(2.18)$ & $19594.42(84.71)$ & $9.18(0.28)$ \\
\cline { 2 - 7 } & 200.00 & $198.13(0.38)$ & $199.09(0.2)$ & $99.66(16.62)$ & $20093.51(1098.63)$ & $10.01(0.11)$ \\
\cline { 2 - 7 } & 250.00 & $254.84(0.56)$ & $255.43(0.57)$ & $137.62(31.26)$ & $18271.90(421.01)$ & $11.28(0.76)$ \\
\cline { 2 - 7 } & 300.00 & $313.38(3.1)$ & $313.36(2.74)$ & $75.98(29.84)$ & $17858.44(1701.94)$ & $16.52(3.26)$ \\
\cline { 2 - 7 } & 450.00 & $385.11(8.86)$ & $327.19(4.45)$ & $134.67(23.46)$ & $18748.64(684.23)$ & $15.48(0.13)$ \\
\hline
\end{tabular}

Values in parentheses are standard deviation

The influence of structure on the load, absorbing energy, and time of boards is shown in Fig. 2. The shapes of the load-time and energy-time curves were different from the initial energy levels, and they were related to the destruction forms.

According to a comparative analysis of the plot of energy versus time in Figs. 2(a) through 2(c), absorbing energy rapidly increased as the time increased, and then it suddenly decreased after the peak, represented at the $50 \mathrm{~J}$ to $150 \mathrm{~J}$ impact energy. It was noted that at the point where the initial energy supplied to the dart was completely transferred to the plate (rebound case), the impact velocity increased, which ultimately resulted in a small drop in the absorption of energy (Belingardi and Vadori 2002). As shown in Figs. 2(d) through $2(\mathrm{~g})$, under the impact energy of $200 \mathrm{~J}$ to $450 \mathrm{~J}$ the energy absorption $v s$. time for the board gradually increased in a linear fashion until it leveled off. When the specimen was run through, the dart did not rebound, and the energy-time curve continued upward due to friction of the perforation hole edges against the lateral surface of the dart (Hu 2010). 

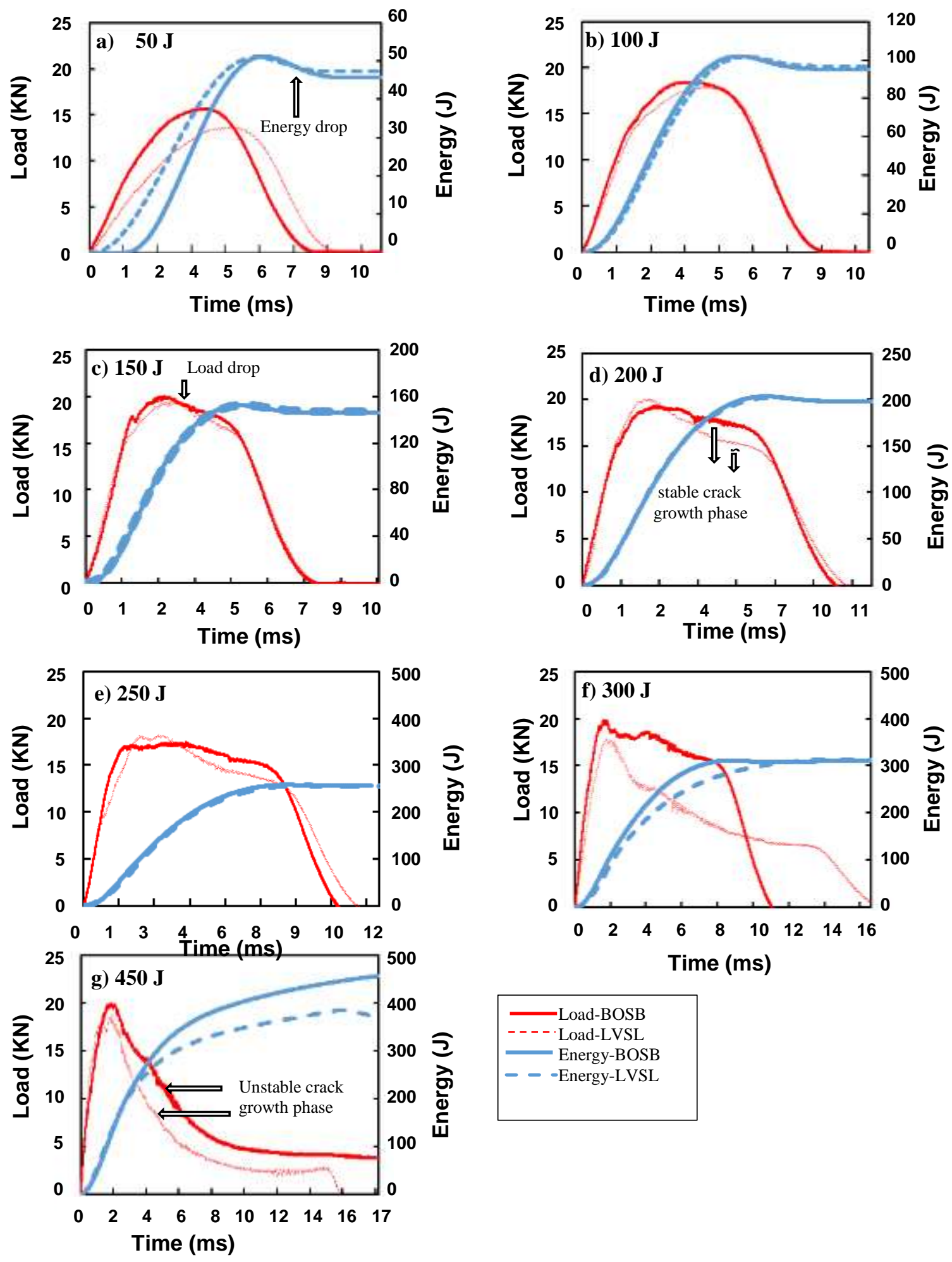

Fig. 2. Force /energy-time history of BOSB and LVSL under different projectile energy ( $50 \mathrm{~J}$ to $450 \mathrm{~J})$. In (d), the area under the load-time platform curve stands for energy produced during the stable crack growth phase. In (f), backward curves after peak load showed an unstable crack growth phase. 
Through analysis of the plot of load versus time in Figs. 2(c) through 2(e), loads rose to the maximum value and then descended smoothly with an obvious decline after the peak under an impact energy of $150 \mathrm{~J}$ to $250 \mathrm{~J}$. The phenomenon can be attributed to the impactor traveling through two materials with significant differences in stiffness during the impact process, and thus stress redistribution leads to the tumbling load drop (Zhang et al. 2013). As shown in Figs. 2(c) through 2(e), when the load reached its maximum value, a platform area appeared on the load-time curve caused by steadily expanding cracks. Correspondingly, a possible mode of failure was fiber breakage, as interior cracks and bending cracks appeared at the bottom layers of specimens (Figs. 3(c) through 3(e), and (c') through (e')). Additionally, it was apparent that the energy produced during the crack growth phase of BOSB was remarkably greater than that of LVSL. This illustrated that the cross lay-up of strands had an inhibitory effect on crack propagation and could noticeably improve the impact resistance life. In Fig. 2(f), the LVSL force-time histories for $300 \mathrm{~J}$ impact is illustrated. The load after peak stress exhibited an obvious drop, and then a plateau appeared. In addition, the impact duration was notably longer than that of BOSB. At an impact energy of $450 \mathrm{~J}$, it was indicated in Fig. 2(g) that the stable crack extension energy of BOSB and LVSL was low. This was because once the main crack formed, the crack rapidly propagated and immediately fractured, which resulted from the absorption of more energy. It was likewise displayed that the unstable crack initiation energy of BOSB was higher than LVSL.

\section{Analysis of Damage Morphology of Untreated Bamboo OSB}

In the study, views of CT images in the central position are depicted in Fig. 3 for different numbers of impacts. The damage area created by the impact event gave an indication of the composite's ability to resist impact, i.e., small damage areas demonstrating good resistance (Khondker et al. 2005). Different damage types were caused by impacts at different energy levels. The delamination size at each unique interface increased with the impact energy level's growth. When the impact energy was $50 \mathrm{~J}$ to 300 $\mathrm{J}$, there were indentation cones with different depths observed from the perpendicular cross-section surface of the impacted laminate. The dent depth gradually increased in the wake of the increasing impact energy. Additionally, the dent-depth of BOSB on the impact site was less than that of the LVSL. The most severe damage was caused when the impact energy $(450 \mathrm{~J})$ was sufficient to cause the impactor to pass through the specimen. Fiber failure occurred at the indentation central line, the delamination damage for higher energies proceeded with the ascending impacted force, and the fabric lamina was penetrated layerby-layer until penetration failure. These phenomena agreed with other reports (Lesser 1997; Hirai et al. 1998; Reid and Zhou 2000).
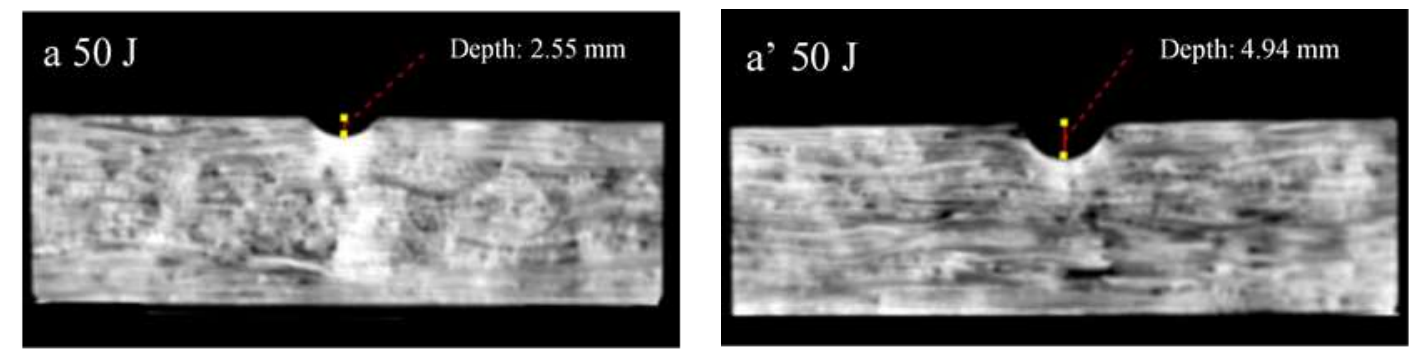

Sun et al. (2018). "Bamboo oriented strand board," BioResources 13(3), 6707-6721. 

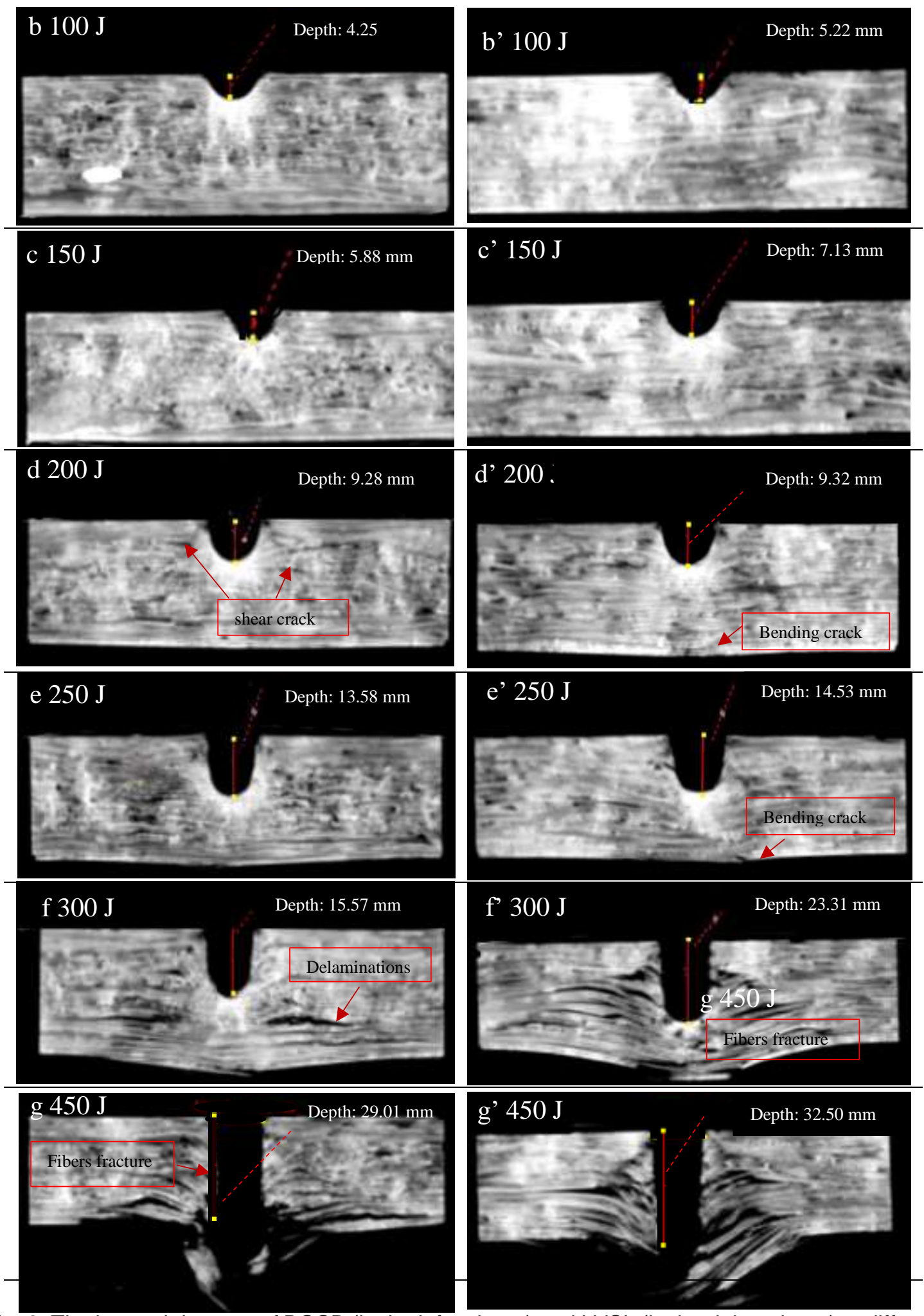

Fig. 3. The internal damage of BOSB (in the left column) and LVSL (in the right column) at different nominal impact energy $(50 \mathrm{~J}$ to $450 \mathrm{~J}$ ) from CT scanning

Low-energy impacts $(50 \mathrm{~J}, 100 \mathrm{~J}$, and $150 \mathrm{~J}$ ) caused compression destruction, and no obvious cracks appeared in both interior boards. Higher-energy impacts (200 J, $250 \mathrm{~J}$, and $300 \mathrm{~J}$ ), for which the impactor barely passed through the specimen, causing fiber 
breakage, interior delaminations, longitudinal interior cracks along the fiber arrangement, and different degrees of bending cracks located around the indentation central line in the bottom layers of the specimens (Figs. 3d through 3f, d' through $\mathrm{f}^{\prime}$ ). An evaluation of laminates indicated that delamination areas were always oriented with their major axes parallel to the fibers, further away from the impact point (indicated by the red arrow in Fig. 3f). This situation was also found in the graphite/epoxy laminate composite materials (AIAA 1985). It was also demonstrated that even if no penetration had broken the interior area of BOSB and LVSL, when the impact energy reached a certain value, obvious cracks and delaminations appeared in interior materials, which intuitively reflected that the hidden damage was far greater than the visual damage observed on the surface caused by low impact levels. By comparing the CT scanning charts for the BOSB and LVSL samples (Fig. $3 \mathrm{f} / \mathrm{f}^{\prime}$ ), there were more internal fractures on the inside layers of LVSL. This indicated that the interlaced discontinuity of bamboo strands and the matrix interface of BOSB contributed effectively to suppressing the crack propagation.

Relatively high energy (450 J), for which the impactor penetrated the specimen, caused fiber compressive/tensile breakage and cracks close to the impact site, as shown in Fig. 3g/g'. The damage morphologies of the penetrated BOSB and LVSL were similar, but the delamination size of the penetrated BOSB was smaller. This indicated that the structure of the reinforced material strongly affected the delamination pattern and area. The analysis was in agreement with previously published articles stating that E-Glass woven composites were superior to unidirectional composites in the protection of damage growth within a smaller area at low-velocity impact (Shyr and Pan 2003; Evci and Gülgeç 2012).

The impact damage mechanism in a laminate constitutes a very complex process. It was a combination of matrix cracking, surface buckling, delamination, fiber shear-out, fiber fracture, and so forth, which usually all interact with each other (Jegley 1992; Belingardi and Vadori 2002). The effect of impact loading on a specimen's deformation was induced by the longitudinal stress waves running parallel to the fiber direction and by the transverse stress waves along the dropping direction of the impactor hammer, generating outward from the impact point (Jiang et al. 2013). The specimens were subjected to compression, tensile, and shear stress under the effect of in-plane and transverse impacting stress waves. Compressive, tensile and shear longitudinal stress waves were likely to induce the matrix and fiber degumming phenomenon, and caused the bamboo fibers to fracture. The transverse stress wave drove the fibers forward with the dropping hammer through the interaction between the resin matrix and the fibers, resulting in energy incorporated in a fairly large area. In comparing longitudinal tension strength, the load capacity in the transverse direction of fibers and the bonding strength between interfaces were much lower. This was consistent with the description in this article by Shyr and Pan (2003). Thus, delamination and fibers cutting off were the key fracture phenomena for bamboo OSB under the impact loadings, as reported in Zhang et al. (2017).

\section{Effects of Immersed-dry Environment}

Comparing Tables 1 and 2, when the impact energy was $50 \mathrm{~J}$ to $300 \mathrm{~J}$, the impact parameters of treated BOSB and LVSL showed no significant difference from untreated ones. However, as illustrated in Table 2, the impact energy (450 J) achieved the required fracture energy, and the specimens were completely destroyed. The total energy, energy at fracture, and peak load of BOSB and LVSL were reduced 19.96\%, 24.19\%, and 19.96\%; $17.15 \%, 17.57 \%$, and $28.46 \%$, respectively, when compared to the untreated specimens at an impact energy of $450 \mathrm{~J}$. It also was observed that the impact resistance of treated BOSB 
and LVSL declined in a humid environment, with BOSB obviously decreased. This observation was consistent with previous experiments by $\mathrm{Fu}$ et al. (2017). The main reasons for the decline in impact resistances in a humid environment were as follows: physical and chemical changes in the cell level and tissue level embracing the hygroscopic expansion of bamboo strands, local aging damage of resin, derivation of micro-cracking, interface delamination, and internal stress relief that led to the size deformation and mechanical property attenuation of plate macroscopically.

The total energy, fracture energy, and maximum load of BOSB after impact were greater than that of LVSL at $14.87 \%, 18.61 \%$, and $14.53 \%$, which indicated that BOSB still exhibited better impact resistance than LVSL after being affected by a damp environment.

Table 2. The Impact of BOSB and LVSL Samples After Treatment

\begin{tabular}{|c|c|c|c|c|c|c|}
\hline Specimens & $\begin{array}{c}\text { Impact } \\
\text { Energy } \\
(\mathrm{J})\end{array}$ & $\begin{array}{c}\text { Total Energy } \\
\text { (J) }\end{array}$ & $\begin{array}{l}\text { Energy at } \\
\text { Fracture }(\mathrm{J})\end{array}$ & $\begin{array}{l}\text { Energy to } \\
\text { Peak Force } \\
\text { (J) }\end{array}$ & Peak Force $(\mathrm{N})$ & $\begin{array}{l}\text { Total Time } \\
\quad(\mathrm{ms})\end{array}$ \\
\hline \multirow{7}{*}{$\begin{array}{c}\text { Treated } \\
\text { BOSB }\end{array}$} & 50.00 & $44.41(0.93)$ & $45.34(0.83)$ & $48.11(2.01)$ & 16686.81(2062.84) & $8.17(0.8)$ \\
\hline & 100.00 & $93.81(1.56)$ & $94.97(1.48)$ & 91.94(5.65) & 19593.47(1744.15) & $8.49(0.65)$ \\
\hline & 150.00 & $144.37(1.33)$ & $145.65(1.04)$ & $130.63(5.49)$ & $21045.61(2704.12)$ & $8.7(0.81)$ \\
\hline & 200.00 & $197.83(3.81)$ & 198.97(3.19) & $80.63(10.49)$ & 19658.52 (3710.68) & $10.05(1.55)$ \\
\hline & 250.00 & $255.15(3.21)$ & $256.19(0.48)$ & $100.67(5.01)$ & $22167.70(2010.22)$ & $10.62(2.3)$ \\
\hline & 300.00 & $309.06(3.71)$ & $309.82(3.7)$ & $81.43(15.82)$ & 20019.65 (649.97) & $12.29(0.05)$ \\
\hline & 450.00 & $374.79(4.26) \mid$ & 331.37(2.67) & $99.48(248.97)$ & $15693.80(8.26)$ & $14.69(2.32)$ \\
\hline \multirow{7}{*}{$\begin{array}{l}\text { Treated } \\
\text { LVSL }\end{array}$} & 50.00 & $48.05(1.69)$ & $48.57(1.61)$ & $47.54(0.35)$ & 11261.91(3513.76) & $10.45(1.95)$ \\
\hline & 100.00 & $96.79(1.02)$ & $97.57(0.68)$ & $92.25(16.19)$ & $17945.28(1234.89)$ & $8.47(1.03)$ \\
\hline & 150.00 & $147.17(3.46)$ & $148.19(3.07)$ & 108.98(24.45) & 19594.40 (3411.08) & $9.18(1.3)$ \\
\hline & 200.00 & 198.13(1.7) & 199.09(1.66) & $99.66(1.24)$ & 20093.55 (313.67) & $10.01(0.71)$ \\
\hline & 250.00 & $254.84(2.87)$ & $255.43(2.23)$ & $137.62(2.77)$ & 18271.94(1873.03) & $11.28(3.91)$ \\
\hline & 300.00 & $313.38(14.1)$ & $293.36(12.84)$ & $75.98(5.11)$ & $17858.41(1499.25)$ & $16.52(4.85)$ \\
\hline & 450.00 & $319.04(5.31)$ & 269.69(9.09) & 68.83(15.64) & $13413.30(8.58)$ & 17.58(2.32) \\
\hline
\end{tabular}

The internal damage of treated BOSB and treated LVSL at nominal impact energy (50-450 J) from CT scanning is shown in Fig. 4. It could be concluded, by making a comparison between treated and non-treated CT scans of boards, that failure types of both strandboards resembled each other. In spite of this similarity, there were some differences the in degree of damage between treated and untreated specimens under higher energy impacts (250J and 300J). There were more interior delaminations and longitudinal interior cracks in treated LVSL than untreated LVSL at impact energy of 250J. Moreover, both treated boards had been penetrated when the impact energy was 300J, which is lower than the perforation energy (450J) of untreated specimens. 

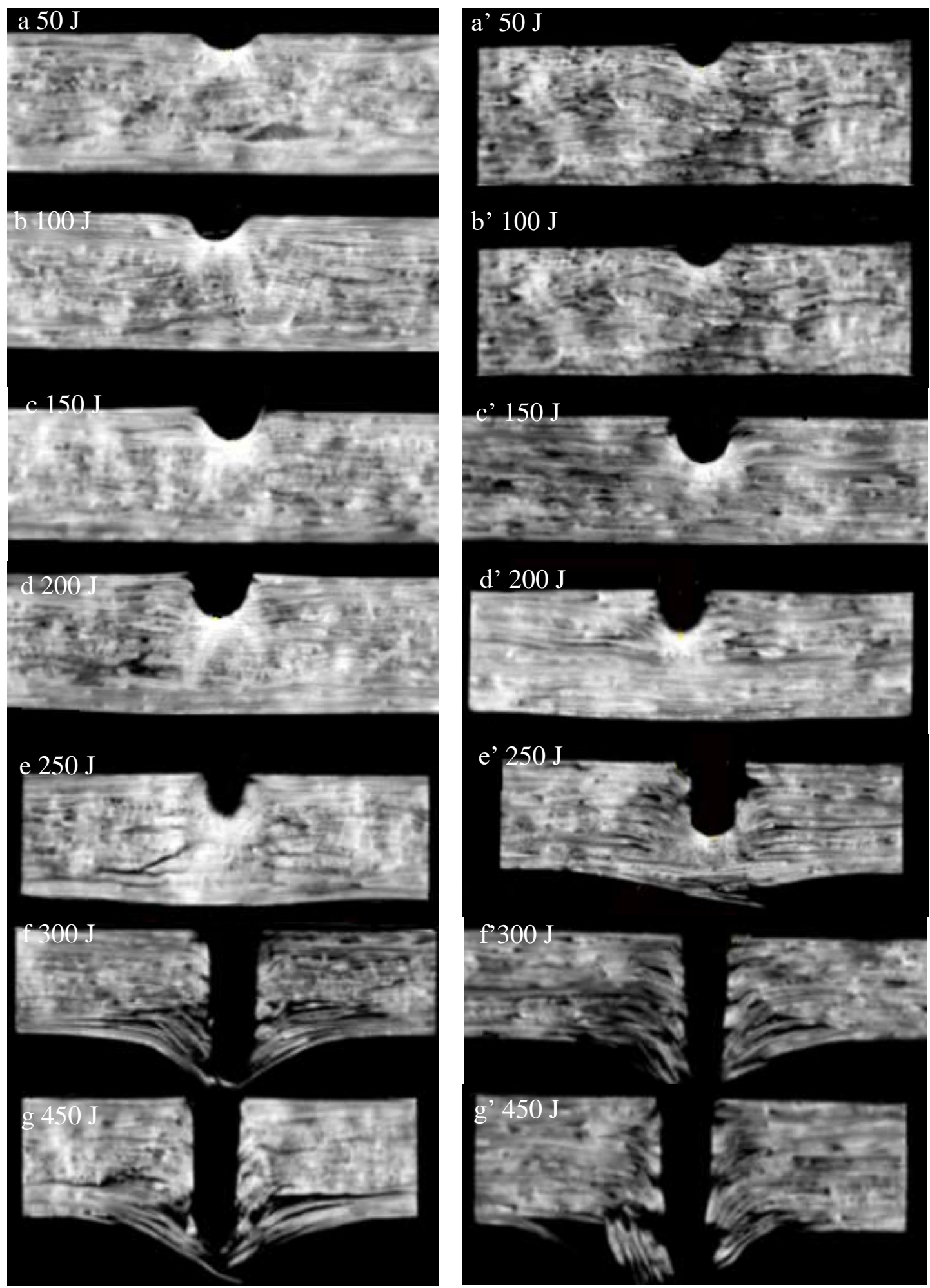

Fig. 4. The internal damage of treated BOSB (in the left column) and treated LVSL (in the right column) at nominal impact energy (50-450 J) from CT scanning 


\section{CONCLUSIONS}

1. The BOSB provided greater large load carrying capacity at impact energies ranging from $50 \mathrm{~J}$ to $450 \mathrm{~J}$ when compared to LVSL. Additionally, BOSB exhibited better impact resistance properties, superior to those of uniaxial lamination board at higher impact energies. A three-layer assembly enhanced the structural integrity of composites and offered better impact damage resistance and tolerance.

2. The shapes of force/energy-time history of BOSB and LVSL were different from the projectile energy levels, and they were related to destruction forms via CT scanning, which was a very effective way to reveal the internal defects or damage of materials under diverse projectile energy. Both materials exhibited similar damage behaviors that included delamination and fiber-cutting for the key fracture phenomena for samples under impact loadings.

3. The total energy, energy at fracture, and peak load of BOSB and LVSL were reduced $19.96 \%, 24.19 \%$, and $19.96 \% ; 17.15 \%, 17.57 \%$, and $28.46 \%$, respectively, when compared to samples before treatment at an impact energy of $450 \mathrm{~J}$. The total energy, fracture energy, and maximum load of BOSB after impact were greater than that of LVSL $(14.87 \%, 18.61 \%$, and $14.53 \%)$, indicating that BOSB still exhibited better impact resistance than LVSL after being affected by a damp environment.

\section{ACKNOWLEDGMENTS}

The authors are grateful for the financial support of the National Key Research \& Development Program of China (2016YFD0600905). The constructive comments from the anonymous reviewers are also greatly appreciated.

\section{REFERENCES CITED}

Alldritt, K., Sinha, A., and Miller, T. H. (2013). "Designing a strand orientation pattern for improved shear properties of oriented strand board," Journal of Materials in Civil Engineering 26(7), 1-9. DOI: 10.1061/(ASCE)MT.1943-5533.0001033

ASTM D3763 (2015). "Standard test method for high speed puncture properties of plastics using load and displacement sensors," ASTM International, West Conshohocken, PA.

ASTM D7136 (2015). "Standard test method for measuring the damage resistance of a fiber-reinforced polymer matrix composite to a drop-weight impact event," ASTM International, West Conshohocken, PA

Avila, A. F., Soares, M. I., and Neto, A. S. (2007). "A study on nanostructured laminated plates behavior under low-velocity impact loadings," International Journal of Impact Engineering 34(1), 28-41. DOI: 10.1016/j.ijimpeng.2006.06.009

Belingardi, G., and Vadori, R. (2002). "Low velocity impact tests of laminate glass-fiberepoxy matrix composite material plates," International Journal of Impact

Engineering 27(2), 213-229. DOI: 10.1016/S0734-743X (01)00040-9 
Chaowana, P. (2013). "Bamboo: An alternative raw material for wood and wood-based composites," Journal of Materials Science Research 2(2), 90-102. DOI: 10.5539/jmsr.v2n2p90

Chen, F., Deng, J., Cheng, H., Li, H., Jiang, Z., Wang, G., Zhao, Q., and Shi, S. Q. (2014). "Impact properties of bamboo bundle laminated veneer lumber by preprocessing densification technology," Journal of Wood Science 60(6), 421-427. DOI: $10.1007 / \mathrm{s} 10086-014-1424-0$

Chen, G., and He, B. (2017). "Stress-strain constitutive relation of OSB under axial loading: An experimental investigation," BioResources 12(3), 6142-6156. DOI: 10.15376/biores.12.3.6142-6156

Dixon, P. G., Malek, S., Semple, K. E., Zhang, P. K., Smith, G. D., and Gibson, L. J. (2017). "Multiscale modelling of moso bamboo oriented strand board," BioResources 12(2), 3166-3181. DOI: 10.15376/biores.12.2.3166-3181

Du, A. L., and Xie, L. S. (2010). "Development and prospect of bamboo oriented strand board," China Forest Products Industry 37(6), 3-6.

Evans, L. M., Margetts, L., Casalegno, V., Lever, L. M., Bushell, J., Lowe, T., Wallwork, A., Young, P., Lindemann, A., Schmidt, M., et al. (2015). "Transient thermal finite element analysis of CFC-Cu ITER monoblock using X-ray tomography data," Fusion Engineering and Design 100, 100-111. DOI: 10.1016/j.fusengdes.2015.04.048

Evci, C., and Gülgeç, M. (2012). "An experimental investigation on the impact response of composite materials," International Journal of Impact Engineering 43(5), 40-51. DOI: 10.1016/j.ijimpeng.2011.11.009

Fu, H. T., Sun, L. C., and Wang, H. G. (2017). "Study on low-velocity impact performance of wood plastic composites/laminated veneer lumber co-extruded composites," Acta Materiae Compositae Sinica 35(1), 200-207. DOI:

10.13801/j.cnki.fhclxb.20170321.005

González, E. V., Maimí, P., Camanho, P. P., Lopes, C. S., and Blanco, N. (2011). "Effects of ply clustering in laminated composite plates under low-velocity impact loading," Composites Science and Technology 71(6), 805-817. DOI: 10.1016/j.compscitech.2010.12.018

Haghdan, S., Tannert, T., and Smith, G. D. (2015). "Wettability and impact performance of wood veneer/polyester composites," BioResources 10(3), 5633-5654. DOI: 10.15376/biores.10.3.5633-5654

Hirai, Y., Hamada, H., and Kim, J. K. (1998). "Impact response of woven glass-fabric composites-II - effect of temperature," Composites Science and Technology 58(1), 119-128. DOI: 10.1016/S0266-3538(97)00112-7

Hu, J. Y. (2010). Research on Low-velocity Impact Properties and Damage Mechanism of Woven Fabric Composite, Master's Thesis, Harbin Institute of Technology, Harbin, IN, China.

Jain, S., Kumar, R., and Jindal, U. C. (1992). "Mechanical behaviour of bamboo and bamboo composite," Journal of Materials Science 27(17), 4598-4604. DOI: 10.1007/BF01165993

Jegley, D. C. (1992). Effect of Low-speed Impact Damage and Damage Location on Behavior of Composite Panels (Report No. N95-28481), National Aeronautics and Space Administration, Hampton, VA, USA.

Jiang, Z., Chen, F., Wang, G., Liu, X., Shi, S. Q., Yu, Z., and Cheng, H. T. (2013). "Bamboo bundle corrugated laminated composites (BLCL). Part II. Damage analysis 
under low velocity impact loading," BioResources 8(1), 923-932. DOI:

10.15376/biores.8.1.923-932

Khondker, O. A., Leong, K. H., Herszberg, I., and Hamada, H. (2005). "Impact and compression-after-impact performance of weft-knitted glass textile composites," Composites Part A: Applied Science \& Manufacturing 36(5), 638-648. DOI: 10.1016/j.compositesa.2004.07.006

Lesser, A. J. (1997). "Effect of resin crosslink density on the impact damage resistance of laminated composites," Polymer Composites 18(1), 16-27. DOI: 10.1002/pc.10257

Liu, H. R., Yan, Y., and Sun, Z. J. (2016). "Impact performance of bamboo /poplar laminated composite," Journal of Nanjing Forestry University 40(6), 157-161. DOI: 10.3969 /j. issn.1000-2006.2016.06.024

Maio, L., Monaco, E., Ricci, F., and Lecce, L. (2013). "Simulation of low velocity impact on composite laminates with progressive failure analysis," Composite Structures 103(103), 75-85. DOI: 10.1016/j.compstruct.2013.02.027

Mei, H., Yu, C. K., Xu, H., and Cheng, L. F. (2015). "The effects of stitched density on low-velocity impact damage of cross-woven carbon fiber reinforced silicon carbide composites," Ceramics International 42(1 Part B), 1762-1768. DOI: 10.1016/j.ceramint.2015.09.137

Meng, Q., Hao, H., and Chen, W. (2016). "Laboratory test and numerical study of structural insulated panel strengthened with glass fibre laminate against windborne debris impact," Construction \& Building Materials 114, 434-446. DOI:

10.1016/j.conbuildmat.2016.03.190

Reid, S. R., and Zhou, G. (2000). Impact Behaviour of Fibre-Reinforced Composite Materials and Structures, Woodhead Publishing Ltd., Cambridge, UK.

Semple, K. E., Zhang, P. K., Smola, M., and Smith, G. D. (2015). "Hybrid oriented strandboards made from moso bamboo (Phyllostachys pubescens, Mazel) and aspen (Populus tremuloides, Michx.): Uniformly mixed single layer uni-directional boards," European Journal of Wood \& Wood Products 73(4), 515-525. DOI: 10.1007/s00107015-0914-0

Shyr, T. W., and Pan, Y. H. (2003). "Impact resistance and damage characteristics of composite laminates," Composite Structures 62(2), 193-203. DOI: 10.1016/S02638223(03)00114-4

Skog, J. (2016). New Forest Industry Production Systems Based on High-Speed CT Scanning (CT-Pro), Wood Wisdom Net Research Programme Final Report 1(17), SP Technical Research Institute of Sweden, Borås, Sweden.

Stürzenbecher, R., Hofstetter, K., Bogensperger, T., Schickhofer, G., and Eberhardsteiner, J. (2010). "Development of high-performance strandboards: Engineering design and experimental investigations," Wood Science \& Technology 44(1), 13-29. DOI: 10.1007/s00226-009-0258-1

Terentiuk, S., and Memari, A. (2012). "In-plane monotonic and cyclic racking load testing of structural insulated panels," Journal of Architectural Engineering 18(4), 261-275. DOI: 10.1061/(ASCE)AE.1943-5568.0000084

Tooski, M. Y., Alderliesten, R. C., Ghajar, R., and Khalili, S. M. R. (2013). "Experimental investigation on distance effects in repeated low velocity impact on fiber-metal laminates," Composite Structures 99(5), 31-40. DOI: 10.1016/j.compstruct.2012.11.045 
Yu, Z. X., Jiang, Z. H., and Wang, G. (2012). "Impact resistance properties of bamboo scrimber," Journal of Northeast Forestry University 40(4), 46-48. DOI: 10.13759/j.cnki.dlxb.2012.04.006

Zhang, D., Chen, L., Sun, Y., and Sun, F. (2013). "Low velocity impact and residual compressive strength after impact properties of UHMWPE/LLDPE composite laminates," Acta Materiae Compositae Sinica 30(S1), 107-111. DOI: 10.13801/j.cnki.fhclxb.2013.s1.031

Zhang, D. D., Sun, Y. N., and Wang, Y. (2017). "Failure behavior and damage mechanism of multiaxial glass fiber reinforced resin matrix composites," Acta Materiae Compositae Sinica 34(2), 381-388. DOI: 10.13801/j.cnki.fhclxb.20160606.004

Zhu, Y. X., Guan, M. J., and Zhang, X. D. (2005). "Studies on impact performance of bamboo strengthened laminated veneer lumber of poplar," Journal of Nanjing Forestry University 29(6), 99-102.

Article submitted: February 22, 2018; Peer review completed: April 9, 2018; Revised version received: April 11, 2018; Accepted: May 13, 2018: Published: July 18, 2018. DOI: 10.15376/biores.13.3.6707-6721 